\title{
Impact of Advance Notice Periods on the Performance Persistence of Hedge Funds
}

\author{
Pascal Gantenbein, Stephan Glatz \\ University of Basel, Basel, Switzerland
}

\begin{abstract}
This paper examines the impact of the advance notice period on hedge fund performance persistence in investors' portfolios. As investors in hedge funds face several trading restrictions related to the funds' common investment terms and conditions, it is hypothesized that the advance notice period generates illiquidity for investors and impairs their ability to benefit from performance persistence in hedge funds. Using a sample of 4,788 hedge funds over a period from 1994 to 2008 and contingency table based standard methodology for returns and Sharpe ratios, the results suggest that accounting for individual funds' advance notice periods has a negative impact on the performance persistence of hedge funds. The proportion of significantly persistent funds declines when incorporating the advance notice period, especially for short time horizons. Furthermore, a considerable part of hedge fund performance persistence is related to asset class-specific terms and conditions, reducing the amount of short-term performance persistence in practice.
\end{abstract}

Keywords: advance notice period, hedge funds, liquidity risk, performance persistence

\section{Introduction}

One of the key questions investors face when making investment decisions is to what extent past performance can be used as an indicator for future performance. Given a relatively high degree of freedom in executing their investment strategies, hedge fund managers are particularly supposed to generate performance persistence since this goes along with the ability to consistently generate a higher or lower performance compared to the peers. While most existing studies on hedge fund performance persistence find strong short-term performance persistence (Agarwal \& Naik, 2000b; Barès, Gibson, \& Gyger, 2003; Baquero \& Verbeek, 2006), this analysis shows that the levels of performance persistence are significantly lower when accounting for individual funds' advance notice periods. This finding is robust across different hedge fund strategies, performance measures, test methods, and equity market conditions.

In general, the advance notice period describes the length of advance notice that the investor must give to the hedge fund manager of his intention to redeem the fund. Typically, the advance notice period lies between 30 and 90 days and thus represents a form of short-term lock-up period that substantially increases the illiquidity risk of hedge fund investments. While studies, such as Getmansky, Lo, and Makarov (2004) and Gibson and Wang (2009), have pointed out that the illiquidity of hedge funds affects the performance of hedge

Pascal Gantenbein, Ph.D., professor, University of Basel, Basel, Switzerland.

Stephan Glatz, Ph.D., University of Basel, Basel, Switzerland.

Correspondence concerning this article should be addressed to Pascal Gantenbein, Faculty of Business and Economics, University of Basel, Peter Merian-Weg 6, 4002 Basel, Switzerland. E-mail: pascal.gantenbein@unibas.ch. 
funds, this study examines the impact of advance notice periods on hedge fund performance persistence.

In a first step, this paper analyzes hedge fund performance without accounting for the advance notice period and documents that the proportion of individual hedge funds exhibiting statistically significant performance persistence considerably declines with a growing time horizon. In this respect, the results basically confirm the general consensus in academic literature, for example, Harri and Brorsen (2004) have observed the highest levels of persistence in the first month, similar to F. Koh, W. Koh, and Teo (2003) who have shown that performance persistence is strongest over the monthly and quarterly time horizon. In this regard, it can be argued that short-term performance persistence varies among different hedge fund strategies and is to some extent driven by valuation biases such as stale prices and the smoothing of returns, meaning that reported returns do not necessarily reflect fair and prevailing market prices, which in turn may cause positive serial correlations of hedge fund returns.

In a second analysis, this paper integrates individual fund's advance notice periods into the existing framework and finds that the advance notice period significantly reduces performance persistence both at an aggregate and the individual fund level. In fact, the impact of the advance notice period on performance persistence is particularly significant at the one and three months' time horizons, which are exactly those time horizons where most other academic studies report the highest levels of performance persistence. In other words, the results indicate that the omission of investment trading restrictions such as the advance notice period helps explain the relatively high levels of short-term performance persistence among hedge funds compared to other asset classes such as mutual funds (Grinblatt \& Titman, 1992; Brown \& Goetzmann, 1995; Carhart, 1997; Bollen \& Busse, 2004; Berk \& Tonks, 2007). Therefore, it is argued that that short-term hedge fund performance persistence is, in practice, significantly smaller than commonly assumed in academic research. By providing quantitative evidence on the impact of advance notice periods on the performance persistence of hedge funds, the empirical findings are also of great practical relevance.

This analysis differs from existing research in at least three aspects: Firstly, it accounts for the individual funds' advance notice period and therefore offers new empirical evidence for the impact of investor trading restrictions on the performance persistence of hedge funds. As a second point, the data sample employed in this study is one of the largest datasets used in academic research for analyzing hedge fund performance, covering several business cycles (including the financial crisis in 2008) and different hedge fund strategies. Thirdly, this analysis employs a variety of different statistical methods and tests for the influence of time horizons and performance measures in order to check for the robustness of the results.

The remainder of the paper is structured as follows: Section 2 provides a brief review of related literature on hedge fund performance persistence; section 3 presents the data basis for the empirical analyses; section 4 describes the applied methodology; section 5 reports the results; and section 6 concludes this study.

\section{Literature Review}

The hedge fund industry has experienced an enormous growth in terms of the number of funds and managed assets in recent years. According to Hedge Fund Research (2009), the number of hedge funds grew from 610 to 9,176 (CAGR of 16.25\%) over the period from 1990 to 2008, for instance, and the hedge funds' assets under management soared from USD $39 \mathrm{bn}$. to 1,407 bn. (CAGR of 22.04\%) at the same time. In this regard, a considerable number of academic studies investigating the performance persistence of hedge funds have been published, in particular due to the greater availability of hedge fund return data since the end of the 1990s. 
As one of the very first studies on performance persistence of hedge funds, Brown, Goetzmann, and Ibbotson (1999) investigated offshore hedge funds. They found no evidence for performance persistence in raw returns or risk-adjusted returns, even if accounting for the different hedge fund styles. In contrast, Agarwal and Naik (2000b) used monthly return data and found that performance persistence is the highest at the quarterly horizon and decreases substantially for the yearly horizon, indicating that persistence among hedge funds is short-term in nature. Furthermore, they show that persistence, whenever present, is not related to the strategy the hedge funds follow, but mainly to the fact that loser funds continue to be losers. In contrast, Jagannathan, Malakhov, and Novikov (2007) reported that persistence is strongly related to funds with superior performance, while there is only little evidence for persistence among inferior funds. Kosowski, Naik, and Teo (2007) also found strong evidence for performance persistence, in particular for the best performing hedge fund managers. While Edwards and Caglayan (2001) found performance persistence among winners and losers for one and two-year time horizons, the results of Capocci and Hübner (2004) document only limited evidence for middle-decile funds and no performance persistence for funds with the best and the worst performance.

Baquero, Horst, and Verbeek (2005) studied hedge fund persistence effects by focusing on the look-ahead bias. Using a weighting procedure to correct for the look-ahead bias, they found evidence of persistence in hedge fund returns at the three- and 12-month horizons, whereas there seems to be no persistence at the 24-month horizon. Similarly, Malkiel and Saha (2005) reported backfill as well as survivorship biases. Further, they found no evidence of persistence at the 12-month horizon. In this context, Horst and Verbeek (2007) reported that performance persistence is higher, if one corrects for the look-ahead bias, in particular, as expected returns in the lower deciles are significantly reduced. Bonadurer (2007) reported significant performance persistence at the one-month horizon, but found no persistence at the three-month horizon, on average. Boyson (2008) argued that performance persistence is strongest among small and young funds. Eling (2009) found evidence of short-term persistence for horizons of up to six months, while the significance of persistence declines with a growing time horizon. Furthermore, he showed that performance persistence can partially be explained by the survivorship and the backfill bias as well as by return smoothing, while it is not related to the use of option-like strategies.

To the best of authors' knowledge, there are no studies on hedge fund performance persistence that explicitly take account of the advance notice period, although there are some contributions investigating the impact of hedge fund terms and conditions on performance, for example, Agarwal, Daniel, and Naik (2005) examined the role of managerial incentives, fund flows, and skills on hedge fund performance. They found that managerial incentives (e.g., incentive fees) and managerial flexibility (e.g., lock-up, notice, and redemption periods) are positively related to the fund's performance. Koh et al. (2003) also found that funds with longer redemption periods generate higher returns. Aragon (2007) discussed the relation between hedge fund returns and restrictions imposed by funds that limit the liquidity for fund investors. He showed that hedge funds with lock-up restrictions display excess returns of about $4 \%$ to $7 \%$ p.a. compared to non-lock-up funds. Aragon argued that funds with greater share restrictions generate higher returns, as share restrictions allow funds to manage illiquid assets more efficiently. Clifford (2008) has studied hedge fund activism and shown that activist hedge funds have longer lock-up and redemption periods than non-activist hedge funds. Gibson and Wang (2009) examined the effect of liquidity risk on the performance of hedge fund portfolio strategies and found that the consideration of liquidity risk reduces alphas to insignificant levels for most portfolio strategies. They 
argued that the outperformance of hedge funds is to a large extent solely a compensation for bearing illiquidity risk.

Overall, the existing academic research does not investigate the impact of investor trading restrictions, such as advance notice periods on the performance persistence so far, but primarily describes the relationship between fund characteristics and fund performance. Moreover, it is evident that despite extensive research on performance persistence of hedge funds, the empirical results of academic studies differ considerably, and knowledge remains incomplete. The results seem to be influenced by factors, such as different methodologies, data sources, investigation periods, measurement models, and the handling of potential biases. While most studies find persistence in the short-term of up to three months, there is limited evidence for persistence at horizons of one year and beyond. Some of other studies emphasize the potential difficulties in exploiting performance persistence, due to hedge fund trading restrictions, such as lock-up periods. However, there is only little empirical evidence of the impact of illiquidity as the result of investor trading restrictions, such as subscription and redemption intervals, the unavailability of timely return data, and lock-up periods.

\section{Data}

The data used in this study is obtained from Hedge Fund Research (HFR) and comprises 12,036 hedge funds (of which 6,585 are live funds and 5,451 are dead funds) between January 1994 and December 2008. HFR is used in a large number of academic studies, such as Agarwal and Naik (2000a), Jagannathan et al. (2007), and Fung, Hsieh, Naik, and Ramadorai (2008). HFR offers a live fund database as well as a dead fund database, comprising both individual hedge funds and fund of hedge funds. The classification is based on five different hedge fund strategies, namely Equity Hedge (EH), Event-Driven (ED), Macro (M), Relative Value (RV), and Fund of Funds (FOF). In accordance with HFR, this study uses the same classification to ensure consistency.

In order to address potential data biases, such as the survivorship bias and backfill bias (e.g., Ackermann, McEnally, \& Ravenscraft, 1999; Liang, 2000), funds have to match different criteria to be selected for the final dataset. The sample selection criteria require funds to have a complete history of their return data (for dead funds until the fund's termination date), assets under management of USD 10 million or above, monthly reporting of return figures (net of fees), and a minimum return history of 24 months. The application of these selection criteria leads to the deletion of 7,248 funds that fail to meet the five selection criteria listed above. The final sample therefore contains 4,788 funds with 2,846 live hedge funds and 1,942 dead hedge funds.

Table 1 summarizes the descriptive statistics of the hedge fund sample for the period from January 1994 to December 2008. It documents the number of funds at the beginning and at the end of the period (columns two and three) as well as the net change in the number of funds in absolute terms and relative terms within the one year period (columns four and five). Using the time series approach, the mean returns and the standard deviation of returns are displayed on an annual (columns six and seven) and monthly basis (columns eight and nine).

As it can be seen from Table 1, the number of funds in the sample substantially grows over time. This is in particular the case for the three-year period from 2005 to 2007 which are the years with the highest average number of funds in the sample. In addition, the consideration of data covering the financial crisis of 2008 has a significant impact on hedge fund performance, since this leads to a substantial decrease in mean returns and to an increase in standard deviations, on average. Furthermore, it can be observed that the mean returns and the 
standard deviation of returns vary considerably over time. Also the corresponding sample funds exhibit different risk-return profiles over time.

Table 1

Descriptive Statistics

\begin{tabular}{lllllllll}
\hline Year & $\begin{array}{l}\text { Total No. of } \\
\text { funds at } \\
\text { beginning }\end{array}$ & $\begin{array}{l}\text { Total No. of } \\
\text { funds at end }\end{array}$ & $\begin{array}{l}\text { Change in } \\
\text { No. of funds }\end{array}$ & $\begin{array}{l}\text { Change in } \\
\text { No. of funds } \\
\text { in \%) }\end{array}$ & $\begin{array}{l}\text { Mean return } \\
\text { p.a. }\end{array}$ & $\begin{array}{l}\text { Std. deviation } \\
\text { p.a. }\end{array}$ & $\begin{array}{l}\text { Mean return } \\
\text { p.m. }\end{array}$ & $\begin{array}{l}\text { Std. deviation } \\
p . m .\end{array}$ \\
\hline 1994 & 337 & 437 & 100 & 0.2967 & 0.0342 & 0.0880 & 0.0028 & 0.0254 \\
1995 & 437 & 574 & 137 & 0.3135 & 0.2056 & 0.0854 & 0.0171 & 0.0247 \\
1996 & 547 & 741 & 167 & 0.2909 & 0.2020 & 0.0825 & 0.0168 & $0-0238$ \\
1997 & 741 & 904 & 163 & 0.2200 & 0.1915 & 0.0896 & 0.0160 & 0.0259 \\
1998 & 904 & 1,128 & 224 & 0.2478 & 0.0587 & 0.1151 & 0.0049 & 0.0332 \\
1999 & 1,128 & 1,433 & 305 & 0.2704 & 0.2620 & 0.1129 & 0.0218 & 0.0326 \\
2000 & 1,433 & 1,759 & 326 & 0.2275 & 0.1468 & 0.1137 & 0.0122 & 0.0328 \\
2001 & 1,759 & 2,162 & 403 & 0.2291 & 0.0963 & 0.0859 & 0.0080 & 0.0248 \\
2002 & 2,162 & 2,642 & 480 & 0.2220 & 0.0448 & 0.0751 & 0.0037 & 0.0217 \\
2003 & 2,642 & 3,072 & 430 & 0.1628 & 0.1749 & 0.0680 & 0.0146 & 0.0196 \\
2004 & 3,072 & 3,499 & 427 & 0.1390 & 0.0937 & 0.0551 & 0.0078 & 0.0159 \\
2005 & 3,499 & 3,820 & 321 & 0.0917 & 0.0957 & 0.0561 & 0.0080 & 0.0162 \\
2006 & 3,820 & 3,955 & 135 & 0.0353 & 0.1232 & 0.0559 & 0.0103 & 0.0161 \\
2007 & 3,955 & 3,657 & -298 & -0.0753 & 0.1140 & 0.0653 & 0.0095 & 0.0189 \\
2008 & 3,657 & 2,846 & -811 & -0.2218 & -0.1865 & 0.1155 & -0.0155 & 0.0333 \\
\hline
\end{tabular}

In order to analyze whether returns are normally distributed, the Jarque-Bera (JB) test statistic is used for each individual fund. As it can be seen, a large proportion of sample funds do not exhibit a normal distribution of returns. In fact, for $83.12 \%$ of all funds, the null hypothesis of normal distribution has to be rejected at the $1 \%$ significance level with two degrees of freedom. Therefore, this study only applies non-parametric tests in the empirical analysis. Furthermore, it tests for the well-known issue of serial correlation in time series data (Getmansky et al., 2004). The Durban-Watson (DW) test statistic indicates a weak positive serial correlation in the aggregate data. However, the levels of serial correlation vary substantially among the different hedge fund strategies. While RV funds exhibit a relatively high level of positive serial correlation (DW test of 1.18), the results, e.g., for M funds, do not indicate positive serial correlation at all (DW test of 1.73). In order to limit the impact of these hedge fund style factors, the performance persistence analysis is conducted individually for each type of hedge fund strategy. Moreover, comparing the performance of live funds and dead funds suggests only small differences in the serial correlation over the period from January 1994 to December 2008. Finally, the survivorship bias in the sample amounts to only $0.02 \%$ per month when using Liang's definition (2000) of survivorship bias.

The unadjusted hedge fund and capital market performance data show the relative attractiveness of hedge funds. In fact, the mean returns of all five hedge fund strategies considerably exceed the returns of the major financial market indices. However, the findings also indicate that differences do exist in the risk-return profile of the different strategies. Moreover, hedge funds exhibit significantly lower risk levels compared to equity markets but also a remarkable correlation with them. These results in general confirm the superior performance that is often attributed to hedge funds (Table 2). 
Table 2

Descriptive Statistics of Aggregate Hedge Fund Indices and Capital Market Returns

\begin{tabular}{lllllrr}
\hline Factors & Min. Return & Max. Return & Mean Return & Std. Deviation & Skew ness & Kurtosis \\
\hline ALLHF & -0.0623 & 0.0629 & 0.0092 & 0.0172 & -0.7606 & 3.2129 \\
EH & -0.0920 & 0.1014 & 0.0114 & 0.0249 & -0.5604 & 2.9937 \\
ED & -0.0920 & 0.0536 & 0.0094 & 0.0186 & -2.0791 & 8.5702 \\
M & -0.0362 & 0.0780 & 0.0111 & 0.0204 & 0.3135 & 0.1947 \\
RV & -0.0888 & 0.0291 & 0.0079 & 0.0126 & -3.7498 & 23.3266 \\
FOF & -0.0630 & 0.0538 & 0.0061 & 0.0161 & -0.9133 & 3.5857 \\
MSW & -0.1646 & 0.0804 & 0.0029 & 0.0412 & -0.9856 & 1.6950 \\
MSEXU S & -0.1572 & 0.0897 & 0.0017 & 0.0426 & -0.9801 & 1.3979 \\
MSEM & -0.2649 & 0.1362 & 0.0070 & 0.0607 & -1.0418 & 2.5516 \\
R3000 & -0.1778 & 0.0803 & 0.0046 & 0.0438 & -0.9408 & 1.7862 \\
Rm-Rf & -0.1715 & 0.0816 & 0.0031 & 0.0443 & -0.9110 & 1.4946 \\
BCG A & -0.0369 & 0.0621 & 0.0051 & 0.0158 & 0.2658 & 0.6921 \\
BCU SA & -0.0336 & 0.0387 & 0.0050 & 0.0113 & -0.2354 & 0.9004 \\
CUSBI G & -0.0338 & 0.0574 & 0.0052 & 0.0120 & 0.3425 & 2.5973 \\
BCG HY & -0.1864 & 0.0769 & 0.0050 & 0.0298 & -2.4149 & 12.6647 \\
JPEM BI & -0.2734 & 0.1012 & 0.0081 & 0.0426 & -2.1368 & 11.3967 \\
BCU ST & -0.0439 & 0.0531 & 0.0054 & 0.0137 & -0.0973 & 1.2224 \\
GSCI & -0.2777 & 0.1766 & 0.0063 & 0.0640 & -0.4421 & 1.6289 \\
TWE XB & -0.0356 & 0.1071 & 0.0009 & 0.0148 & 2.1176 & 15.3546 \\
SM B & -0.1160 & 0.1462 & 0.0019 & 0.0336 & 0.4603 & 1.9898 \\
HML & -0.2079 & 0.1492 & 0.0004 & 0.0412 & -0.6590 & 5.5862 \\
MOM & -0.2504 & 0.1835 & 0.0087 & 0.0506 & -0.5629 & 4.8999 \\
\hline Notes. The & Show & 0.969 &
\end{tabular}

Notes. The table shows descriptive statistics of aggregate hedge fund indices and capital market data using the time series approach; the dataset covers the period from January 1994 to December 2008; ALLHF: hedge fund sample; EH: equity hedge; ED: event-driven; M: macro; RV: relative value; FOF: fund of funds; MSW: MSCI world; MSEXUS: MSCI world excluding the U.S.; MSEM: MSCI emerging markets; R3000: russell 3000; Rm-Rf: excess return on the equity market; BCGA: barclays capital global aggregate; BCUSA: barclays capital us aggregate; CUSBIG: citigroup us broad investment grade; BCGHY: barclays capital global high yield; JPEMBI: J.P. morgan embi global; BCUST: barclays capital global US treasury; GSCI: S\&P GSCI total return index; TWEXB: trade weighted exchange index broad; SMB: small minus big factor; HML: high minus low factor; and MOM: momentum factor.

\section{Methodology}

This analysis covers the period from January 1994 to December 2008. Consequently, a maximum number of 180 time intervals with a one-month time horizon can be considered. The performance persistence is examined across four different time horizons, namely monthly, quarterly, semi-annual, and annual investment periods. The performance is measured by the (net) return and the Sharpe ratio. Despite some criticism regarding these two concepts, the net return and the Sharpe ratio are among the most widely used hedge fund performance measures. As criticism, for example, it is argued that the potential asymmetric return distribution leads to an underestimation of risk and to an overestimation of return. With respect to the analysis of performance persistence, however, this criticism is less important, because the performance measures are used as a relative measure within the hedge fund strategies. This is crucial, since a comparison of hedge funds exhibiting significantly different levels of systematic risk and style factors might otherwise produce seriously distorted results. Therefore, this paper always investigates hedge fund performance persistence within a certain 
hedge fund strategy. Thus, the existence of different levels of systematic risk and style factors is not eliminated, but the impact can be significantly reduced. As for the quality of the Sharpe ratio, for example, Eling and Schuhmacher (2007) compared the ratio with 12 other performance measures and found a virtually identical rank ordering across hedge funds.

Furthermore, the two measures represent reliable and accurate tools for investigating hedge fund performance persistence. With the cross-product ratio test and the Chi-square test, two-period non-parametric statistical procedures based on contingency tables are applied. The cross-product ratio is sometimes also called odds ratio (Brown \& Goetzmann, 1995). These two methods provide relatively robust results in the presence of potential data biases and can be applied also for non-normally distributed data. Carpenter and Lynch (1999) found that the Chi-square test is well-specified and powerful for large samples and more robust in case of survivorship bias compared to other test methodologies, for instance. Moreover, they yield robust results, despite a limited length of time series data.

The identification of winner and loser funds is based on contingency tables. Funds performing better than the median fund are called winners (W), while funds with a lower performance are called losers (L). Specifically, based on the performance measures, a fund is called a winner (loser), if it exhibits a return or Sharpe ratio above (below) the respective median values of several funds in the same strategy type and within the same period. Since a winner (loser) fund in the first period (formation period) can be a winner (loser) fund in the second period (test period), there are four potential outcomes: winner/winner (WW), winner/loser (WL), loser/winner (LW), and loser/loser (LL). If the winners and losers were equally distributed, values of $25 \%$ would be expected. Persistence in the two-period case is given, when a winner (loser) fund in one period keeps being a winner (loser) fund in the following period, therefore either in case of WW or LL. Conversely, independence of performance is assumed, when winner (loser) funds in one period turn out to be loser (winner) funds in the subsequent period.

Furthermore, the Chi-square test has been frequently used in the past for analyzing hedge fund performance persistence (Park \& Staum, 1998; Agarwal \& Naik, 2000b; Malkiel \& Saha, 2005). In a Chi-square test, the observed frequency distribution is compared to the expected theoretical distribution, for example, the observed distribution of the four possible outcomes (WW, LL, WL, and LW) can be compared to the $25 \%$ of the expected theoretical distribution. Statistically, significant performance persistence at $10 \%$, $5 \%$, and $1 \%$ levels is indicated by $X^{2}$ values greater than $2.71,3.84$, and 6.63 , respectively. In accordance with other studies such as Agarwal and Naik (2000b) and Eling (2009), the Chi-square statistic is calculated as follows:

$$
X^{2}=\frac{(\mathrm{WW}-D 1)^{2}}{D 1}+\frac{(\mathrm{WL}-D 2)^{2}}{D 2}+\frac{(\mathrm{LW}-D 3)^{2}}{D 3}+\frac{(\mathrm{LL}-D 4)^{2}}{D 4}
$$

with

$$
\begin{gathered}
D 1=\frac{(\mathrm{WW}+\mathrm{LW}) \times(\mathrm{WW}+\mathrm{LW})}{N} \quad D 2=\frac{(\mathrm{WW}+\mathrm{WL}) \times(\mathrm{WL}+\mathrm{LL})}{N} \\
D 3=\frac{(\mathrm{LW}+\mathrm{LL}) \times(\mathrm{WW}+\mathrm{LW})}{N} \quad D 4=\frac{(\mathrm{LW}+\mathrm{LL}) \times(\mathrm{WL}+\mathrm{LL})}{N}
\end{gathered}
$$


Further, the cross-product ratio (CPR) is used, which describes the relationship between persistent funds and funds without persistence. The CPR shows the relationship both in terms of direction and intensity:

$$
\mathrm{CPR}=\frac{\mathrm{WW} \times \mathrm{LL}}{\mathrm{WL} \times \mathrm{LW}}
$$

A lack of performance persistence would mean that the CPR is equal to one. The statistical significance of the CPR can be tested by means of the Z-statistic, e.g., Z-statistics with values greater than 1.64, 1.96, and 2.58 indicate performance persistence at significance levels of $10 \%, 5 \%$, and $1 \%$ :

$$
Z=\frac{\ln (\mathrm{CPR})}{\sqrt{\frac{1}{\mathrm{WW}}+\frac{1}{\mathrm{WL}}+\frac{1}{\mathrm{LW}}+\frac{1}{\mathrm{LL}}}}
$$

The described methodological framework serves as a standard approach in this analysis. Gantenbein, Glatz, and Zimmermann (2013) used the same methodology for testing performance persistence across bear and bull markets. However, in order to account for the advance notice period, further adjustments are needed. Since the relevant information about the advance notice period for each individual sample fund is available from the HFR database, it is possible to estimate the impact of the advance notice period on performance persistence. More specifically, the following procedure is applied: In a first step, the advance notice period is expressed in months for each sample fund, for example, if a fund has a 45-day advance notice period, the effective time lag is two months. Although trading might not only be possible on a month-end basis in reality, there are other factors of illiquidity justifying this procedure. Secondly, the advance notice period which presents an additional illiquidity risk is then linked to the specific time horizons on an individual fund basis, for example, knowing that a fund has a de facto two-month notice period, it is identified whether the fund is a loser or winner in the period $X+$ two months. Thirdly, the corresponding pairs of winners and losers are formed. Overall, this approach produces a more accurate picture of the practical investment restrictions that hedge fund investors are exposed to in reality. In this respect, the employed methodological framework provides an efficient, reliable, and robust basis for analyzing hedge fund performance persistence.

For simplicity, the study does not account for initial lock-up periods. At this stage, it is also assumed that investors immediately receive all information on fund performance, without the usual delay. However, in reality, fund performance is typically only available some time, e.g. two weeks, after the month's end. Furthermore, subscription and redemption periods are not considered here.

\section{Results}

This section presents the results of the empirical analysis about the impact of the advanced notice period on performance persistence for the sample of 4,788 hedge funds over the period from 1994 to 2008. In general, the results are displayed both on an aggregate level as well as individually. "Aggregate level" means that the number of outcomes (i.e., WW, WL, LW, and LL) is presented on a hedge fund strategy-level. If the analysis is conducted on an "individual level", the outcomes show the proportion of funds exhibiting performance persistence within a specific strategy. In this case, the results of the individual funds are compared with each other, displaying the proportion of funds exhibiting a statistically significant level of performance persistence. 
Table 3 shows the percentage of funds exhibiting statistically significant performance persistence (at the $5 \%$ level of significance) for the base case. The results of the five hedge fund strategies are displayed for the one-, three-, six-, and 12-month time horizons. The methods employed include the Chi-square test and the cross-product ratio test. Furthermore, the table compares the results using the net return and the Sharpe ratio as performance measures. The investigation period is from January 1994 to December 2008.

Table 3

Performance Persistence in Hedge Funds

\begin{tabular}{|c|c|c|c|c|c|c|c|c|}
\hline \multirow{3}{*}{ Base Case } & \multicolumn{8}{|c|}{ Return } \\
\hline & \multicolumn{4}{|c|}{ Chi-square test (5\%-level of significance) } & \multicolumn{4}{|c|}{ Cross-product ratio test (5\%-level of significance) } \\
\hline & $\begin{array}{l}\text { 1-month } \\
\text { horizon }\end{array}$ & $\begin{array}{l}\text { 3-month } \\
\text { horizon }\end{array}$ & $\begin{array}{l}\text { 6-month } \\
\text { horizon }\end{array}$ & $\begin{array}{l}12 \text {-month } \\
\text { horizon }\end{array}$ & $\begin{array}{l}\text { 1-month } \\
\text { horizon }\end{array}$ & $\begin{array}{l}\text { 3-month } \\
\text { horizon }\end{array}$ & $\begin{array}{l}\text { 6-month } \\
\text { horizon }\end{array}$ & $\begin{array}{l}\text { 12-month } \\
\text { horizon }\end{array}$ \\
\hline Equity Hedge & $12.36 \%$ & $7.29 \%$ & $5.69 \%$ & $2.63 \%$ & $10.68 \%$ & $3.05 \%$ & $3.25 \%$ & $0.45 \%$ \\
\hline Event-Driven & $23.92 \%$ & $9.18 \%$ & $7.84 \%$ & $3.35 \%$ & $22.73 \%$ & $5.48 \%$ & $4.42 \%$ & $0.00 \%$ \\
\hline Macro & $6.50 \%$ & $7.08 \%$ & $5.30 \%$ & $2.62 \%$ & $5.06 \%$ & $1.71 \%$ & $1.44 \%$ & $0.00 \%$ \\
\hline $\begin{array}{l}\text { Relative } \\
\text { Value }\end{array}$ & $33.31 \%$ & $11.65 \%$ & $7.55 \%$ & $1.78 \%$ & $31.96 \%$ & $8.96 \%$ & $4.31 \%$ & $0.00 \%$ \\
\hline $\begin{array}{l}\text { Fund of } \\
\text { Funds }\end{array}$ & $17.65 \%$ & $7.92 \%$ & $6.75 \%$ & $1.83 \%$ & $16.5 \%$ & $4.70 \%$ & $3.73 \%$ & $0.00 \%$ \\
\hline Average & $18.71 \%$ & $8.62 \%$ & $6.63 \%$ & $2.44 \%$ & $17.40 \%$ & $4.78 \%$ & $3.43 \%$ & $0.09 \%$ \\
\hline
\end{tabular}

\begin{tabular}{|c|c|c|c|c|c|c|c|c|}
\hline \multirow{3}{*}{ Base Case } & \multicolumn{8}{|c|}{ Sharpe Ratio } \\
\hline & \multicolumn{4}{|c|}{ Chi-square test (5\%-level of significance) } & \multicolumn{4}{|c|}{ Cross-product ratio test (5\%-level of significance) } \\
\hline & $\begin{array}{l}\text { 1-month } \\
\text { horizon }\end{array}$ & $\begin{array}{l}\text { 3-month } \\
\text { horizon }\end{array}$ & $\begin{array}{l}\text { 6-month } \\
\text { horizon }\end{array}$ & $\begin{array}{l}\text { 12-month } \\
\text { horizon }\end{array}$ & $\begin{array}{l}\text { 1-month } \\
\text { horizon }\end{array}$ & $\begin{array}{l}\text { 3-month } \\
\text { horizon }\end{array}$ & $\begin{array}{l}\text { 6-month } \\
\text { horizon }\end{array}$ & $\begin{array}{l}\text { 12-month } \\
\text { horizon }\end{array}$ \\
\hline Equity Hedge & $9.61 \%$ & $7.48 \%$ & $5.74 \%$ & $2.67 \%$ & $8.24 \%$ & $3.4 \%$ & $3.46 \%$ & $0.91 \%$ \\
\hline Event-Driven & $21.93 \%$ & $8.54 \%$ & $8.60 \%$ & $2.35 \%$ & $20.77 \%$ & $6.98 \%$ & $6.39 \%$ & $1.69 \%$ \\
\hline Macro & $8.62 \%$ & $6.58 \%$ & $6.26 \%$ & $4.05 \%$ & $6.85 \%$ & $2.46 \%$ & $1.81 \%$ & $0.00 \%$ \\
\hline $\begin{array}{l}\text { Relative } \\
\text { Value }\end{array}$ & $29.03 \%$ & $12.44 \%$ & $5.67 \%$ & $3.11 \% \%$ & $28.25 \%$ & $8.58 \%$ & $4.60 \%$ & $0.00 \%$ \\
\hline $\begin{array}{l}\text { Fund of } \\
\text { Funds }\end{array}$ & $16.75 \%$ & $7.47 \%$ & $5.94 \%$ & $2.44 \%$ & $15.51 \%$ & $5.33 \%$ & $3.47 \%$ & $0.27 \%$ \\
\hline Average & $17.19 \%$ & $8.50 \%$ & $6.44 \%$ & $2.92 \%$ & $15.93 \%$ & $5.36 \%$ & $3.95 \%$ & $0.58 \%$ \\
\hline
\end{tabular}

\section{The Base Case}

In the base case, the proportion of individual hedge funds exhibiting statistically significant persistence levels strongly declines with an increasing length of the time horizon. At the one-month horizon, $18.71 \%$ of funds display performance persistence at the $5 \%$ level of significance, on average. However, the proportion decreases to only $2.44 \%$ at the 12 -month horizon, for instance. Here, the return is used as the performance measure and the Chi-square test as the statistical methodology.

While there are considerable differences between the five hedge fund strategies with regard to the proportion of persistent funds, the general trend of decreasing persistence is apparent for funds in all five strategies, particularly at short-term horizons of up to three months. Hereby, the Chi-square test leads to higher proportions of individually persistent funds than the cross-product ratio test, on average, in particular for time horizons of up to six months. With respect to using the net return versus the Sharpe ratio as a performance measure, the results do not indicate that the level of performance persistence would significantly be related to the type of performance measure.

Table 4 shows the results on an aggregate fund basis. The analysis documents performance persistence at 
statistically significant levels for the vast majority of strategies and time horizons. The hypothesis that performance persistence is absent for the aggregate sample and for all four time horizons has to be rejected at the $5 \%$ significance level. Similar to the results at the individual fund level, on an aggregate basis, RV funds exhibit the highest level of performance persistence, while $\mathrm{M}$ funds display the lowest levels of persistence.

Table 4

Contingency Tables for All Hedge Funds in the Sample

\begin{tabular}{|c|c|c|c|c|c|c|c|}
\hline \multicolumn{4}{|c|}{ ALLHF-ANP_-Base-Return-1-month } & \multicolumn{4}{|c|}{ ALLHF-ANP-Base-Return-3-month } \\
\hline \multirow[t]{2}{*}{$\begin{array}{l}\text { No. of obs. } \\
\% \text { of } \mathrm{N} \\
\% \text { of Col } \\
\% \text { of Row }\end{array}$} & Winner 2 & Loser 2 & & $\begin{array}{l}\text { No. of obs. } \\
\% \text { of } \mathrm{N} \\
\% \text { of } \mathrm{Col} \\
\% \text { of Row } \\
\end{array}$ & Winner 2 & Loser 2 & \\
\hline & 105,314 & 81,538 & 186.852 & & 33,357 & 28,816 & 60,173 \\
\hline \multirow[t]{4}{*}{ Winner 1} & 0.2822 & 0.2185 & 0.5006 & Winner 1 & 0.2785 & 0.2239 & 0.5024 \\
\hline & 0.5644 & 0.4368 & & & 0.5587 & 0.4465 & \\
\hline & 0.5636 & 0.4364 & & & 0.5544 & 0.4456 & \\
\hline & 81,278 & 105,124 & 186,402 & & 26,352 & 33,245 & 59,597 \\
\hline \multirow[t]{5}{*}{ Loser 1} & 0.2178 & 0.2816 & 0.4994 & Loser 1 & 0.2200 & 0.2776 & 0.4976 \\
\hline & 0.4356 & 0.5632 & & & 0.4413 & 0.5535 & \\
\hline & 0.4360 & 0.5640 & & & 0.4422 & 0.5578 & \\
\hline & 186,592 & 186,662 & 373,254 & & 59,709 & 60,061 & 119,770 \\
\hline & 0.4999 & 0.5001 & & & 0.4985 & 0.5015 & \\
\hline \multicolumn{4}{|c|}{ ALLHF-ANP—Base-Return—6-month } & \multicolumn{4}{|c|}{ ALLHF_ANP_Base-Return-12-month } \\
\hline \multirow[t]{2}{*}{$\begin{array}{l}\text { No. of obs. } \\
\% \text { of } \mathrm{N} \\
\% \text { of Col } \\
\% \text { of Row }\end{array}$} & Winner 2 & Loser 2 & & $\begin{array}{l}\text { No. of obs. } \\
\% \text { of } \mathrm{N} \\
\% \text { of } \mathrm{Col} \\
\% \text { of Row }\end{array}$ & Winner 2 & Loser 2 & \\
\hline & 16,584 & 11,841 & 28,425 & & 6,905 & 5,458 & 12,363 \\
\hline \multirow[t]{4}{*}{ Winner 1} & 0.2955 & 0.2110 & 0.5064 & Winner 1 & 0.2867 & 0.2266 & 0.5133 \\
\hline & 0.5961 & 0.4182 & & & 0.5896 & 0.4412 & \\
\hline & 0.5834 & 0.4166 & & & 0.5585 & 0.4415 & \\
\hline & 11,235 & 16,470 & 27,705 & & 4,807 & 6,913 & 11,720 \\
\hline \multirow[t]{5}{*}{ Loser 1} & 0.2002 & 0.2934 & 0.4936 & Loser 1 & 0.1996 & 0.2870 & 0.4867 \\
\hline & 0.4039 & 0.5818 & & & 0.4104 & 0.5588 & \\
\hline & 0.4055 & 0.5945 & & & 0.4102 & 0.5898 & \\
\hline & 27,819 & 28,311 & 56,130 & & 11,712 & 12,371 & 24,083 \\
\hline & 0.4956 & 0.5044 & & & 0.4863 & 0.5137 & \\
\hline
\end{tabular}

\section{The Advance Notice Period Case}

For the advance notice period case, the performance at an individual fund level is adjusted as described above. The proportion of funds exhibiting statistically significant levels of performance persistence, on average, is below $8.50 \%$ for all four time horizons, for example, only $8.29 \%$ of the sample funds display performance persistence for the one-month horizon at a $5 \%$ significance level, when using the return as the performance measure and the Chi-square test. Similar to the base case, in the ANP-case, the proportion of funds exhibiting statistically significant levels of performance persistence declines with an increasing time horizon. Unlike with the return, the usage of the Sharpe ratio as a performance measure leads to a higher percentage of individual funds exhibiting performance persistence. Furthermore, the proportion of persistent funds differs among the 
five hedge fund strategies. The results show that the Chi-square test leads to a higher number of persistent funds than the cross-product test, in particular for the six- and 12-month horizons.

Table 4 reports the contingency tables of the aggregate hedge fund sample (ALLHF) for the one-, three-, six-, and 12-month time horizons for the base case. The two-times-two contingency tables show the proportion of winners and losers in a two-period framework. Here, the return is used as the performance measure. Each contingency table displays (a) the number of observations in each of the four quadrants, (b) the percentage of specific observations in relation to the total number of observations (in bold letters), (c) the percentage of specific observations in relation to the total number of observations in the column, and (d) the percentage of specific observations in relation to the total number of observations in the row. The investigation period is from January 1994 to December 2008.

Table 5

Performance Persistence in Hedge Funds With Advance Notice Period

\begin{tabular}{|c|c|c|c|c|c|c|c|c|}
\hline \multirow{3}{*}{ ANP-case } & \multicolumn{8}{|c|}{ Return } \\
\hline & \multicolumn{4}{|c|}{ Chi-square test (5\% level of significance) } & \multicolumn{4}{|c|}{ Cross product ratio test ( $5 \%$ level of significance) } \\
\hline & $\begin{array}{l}\text { 1-month } \\
\text { horizon }\end{array}$ & $\begin{array}{l}\text { 3-month } \\
\text { horizon }\end{array}$ & $\begin{array}{l}\text { 6-month } \\
\text { horizon }\end{array}$ & $\begin{array}{l}\text { 12-month } \\
\text { horizon }\end{array}$ & $\begin{array}{l}\text { 1-month } \\
\text { horizon }\end{array}$ & $\begin{array}{l}\text { 3-month } \\
\text { horizon }\end{array}$ & $\begin{array}{l}\text { 6-month } \\
\text { horizon }\end{array}$ & $\begin{array}{l}\text { 12-month } \\
\text { horizon }\end{array}$ \\
\hline Equity Hedge & $5.78 \%$ & $6.77 \%$ & $5.65 \%$ & $2.70 \%$ & $3.54 \%$ & $3.04 \%$ & $1.83 \%$ & $0.00 \%$ \\
\hline Event-Driven & $10.05 \%$ & $6.10 \%$ & $6.96 \%$ & $4.27 \%$ & $8.67 \%$ & $4.36 \%$ & $2.99 \%$ & $0.00 \%$ \\
\hline Macro & $7.00 \%$ & $5.62 \%$ & $5.94 \%$ & $5.52 \%$ & $1.96 \%$ & $1.33 \%$ & $1.19 \%$ & $0.00 \%$ \\
\hline Relative Value & $12.89 \%$ & $8.43 \%$ & $4.61 \%$ & $2.78 \%$ & $10.42 \%$ & $4.68 \%$ & $1.36 \%$ & $0.00 \%$ \\
\hline Fund of Funds & $5.70 \%$ & $5.08 \%$ & $3.82 \%$ & $3.62 \%$ & $3.99 \%$ & $2.34 \%$ & $1.70 \%$ & $0.00 \%$ \\
\hline Average & $8.29 \%$ & $6.40 \%$ & $5.39 \%$ & $3.78 \%$ & $5.72 \%$ & $3.15 \%$ & $1.81 \%$ & $0.00 \%$ \\
\hline \multirow{3}{*}{ ANP-case } & \multicolumn{8}{|c|}{ Sharpe Ratio } \\
\hline & \multicolumn{4}{|c|}{ Chi-square test ( $5 \%$ level of significance) } & \multicolumn{4}{|c|}{ Cross product ratio test ( $5 \%$ level of significance) } \\
\hline & $\begin{array}{l}\text { 1-month } \\
\text { horizon }\end{array}$ & $\begin{array}{l}\text { 3-month } \\
\text { horizon }\end{array}$ & $\begin{array}{l}\text { 6-month } \\
\text { horizon }\end{array}$ & $\begin{array}{l}\text { 12-month } \\
\text { horizon }\end{array}$ & $\begin{array}{l}\text { 1-month } \\
\text { horizon }\end{array}$ & $\begin{array}{l}\text { 3-month } \\
\text { horizon }\end{array}$ & $\begin{array}{l}\text { 6-month } \\
\text { horizon }\end{array}$ & $\begin{array}{l}\text { 12-month } \\
\text { horizon }\end{array}$ \\
\hline Equity Hedge & $5.66 \%$ & $5.60 \%$ & $5.72 \%$ & $3.90 \%$ & $3.35 \%$ & $3.59 \%$ & $2.00 \%$ & $1.89 \%$ \\
\hline Event-Driven & $11.33 \%$ & $7.90 \%$ & $8.45 \%$ & $4.87 \%$ & $9.56 \%$ & $6.03 \%$ & $5.31 \%$ & $5.15 \%$ \\
\hline Macro & $6.84 \%$ & $6.92 \%$ & $6.27 \%$ & $5.02 \%$ & $2.44 \%$ & $2.42 \%$ & $1.40 \%$ & $0.65 \%$ \\
\hline Relative Value & $12.67 \%$ & $8.37 \%$ & $4.62 \%$ & $1.68 \%$ & $10.37 \%$ & $6.07 \%$ & $2.76 \%$ & $1.85 \%$ \\
\hline Fund of Funds & $5.98 \%$ & $5.50 \%$ & $5.46 \%$ & $3.87 \%$ & $3.49 \%$ & $3.63 \%$ & $1.78 \%$ & $0.36 \%$ \\
\hline Average & $8.50 \%$ & $6.86 \%$ & $6.10 \%$ & $3.87 \%$ & $5.84 \%$ & $4.35 \%$ & $2.65 \%$ & $1.98 \%$ \\
\hline
\end{tabular}

Table 5 shows the percentage of funds exhibiting statistically significant performance persistence (at the $5 \%$ level of significance) for the advance notice period (ANP) case. The results of the five hedge fund strategies are displayed for the one-, three-, six-, and 12-month time horizons. The methods employed include the Chi-square test and the cross-product ratio test. Furthermore, the table compares the results based on the return and the Sharpe ratio as performance measures. The investigation period is from January 1994 to December 2008.

Table 6 reports the aggregate results for the four different time horizons using the return as the performance measure. At an aggregate level, the two-times-two contingency tables provide evidence of statistically significant levels of performance persistence. This is true at the $5 \%$ significance level for the chi-square test as well as for the cross-product ratio test. In fact, persistent winners (WW) and persistent losers (LL) account for significantly more than $25 \%$ of the outcomes at each of the four time horizons. Therefore, 
compared to the analysis on an individual fund basis, the aggregate results reveal a stronger persistence among hedge funds, which might be due to momentum effects in hedge fund returns.

Table 6

Contingency Tables for All Hedge Funds in the Sample With Advance Notice Period

\begin{tabular}{|c|c|c|c|c|c|c|c|}
\hline \multicolumn{4}{|c|}{ ALLHF-ANP-Return-1-month } & \multicolumn{4}{|c|}{ ALLHF-ANP-Return-3-month } \\
\hline \multirow[t]{2}{*}{$\begin{array}{l}\text { No. of obs. } \\
\% \text { of } \mathrm{N} \\
\% \text { of Col } \\
\% \text { of Row } \\
\end{array}$} & Winner 2 & Loser 2 & & $\begin{array}{l}\text { No. of obs. } \\
\% \text { of } N \\
\% \text { of Col } \\
\% \text { of Row } \\
\end{array}$ & Winner 2 & Loser 2 & \\
\hline & 96,018 & 86,523 & 182.541 & & 31,798 & 26,459 & 58,257 \\
\hline \multirow[t]{4}{*}{ Winner 1} & 0.2639 & 0.2378 & 0.5017 & Winner 1 & 0.2751 & 0.2289 & 0.5041 \\
\hline & 0.5290 & 0.4745 & & & 0.5534 & 0.4553 & \\
\hline & 0.5260 & 0.4740 & & & 0.5458 & 0.4542 & \\
\hline & 85,491 & 95,814 & 181,305 & & 25,661 & 31,650 & 57,311 \\
\hline \multirow[t]{5}{*}{ Loser 1} & 0.2350 & 0.2633 & 0,4983 & Loser 1 & 0.2220 & 0.2739 & 0.4959 \\
\hline & 0.4710 & 0.5255 & & & 0.4466 & 0.5447 & \\
\hline & 0.4715 & 0.5285 & & & 0.4477 & 0.5523 & \\
\hline & 181,509 & 182,337 & 383846 & & 57,459 & 58,109 & 115,568 \\
\hline & 0.4989 & 0.5011 & & & 0.4972 & 0.5028 & \\
\hline \multicolumn{4}{|c|}{ ALLHF-ANP_-Return-6-month } & \multicolumn{4}{|c|}{ ALLHF-ANP_Return-12-month } \\
\hline \multirow[t]{2}{*}{$\begin{array}{l}\text { No. of obs. } \\
\% \text { of } \mathrm{N} \\
\% \text { of Col } \\
\% \text { of Row }\end{array}$} & Winner 2 & Loser 2 & & $\begin{array}{l}\text { No. of obs. } \\
\% \text { of } N \\
\% \text { of Col } \\
\% \text { of Row }\end{array}$ & Winner 2 & Loser 2 & \\
\hline & 14,773 & 11,958 & 26,731 & & 5,840 & 4,963 & 10,803 \\
\hline \multirow[t]{4}{*}{ Winner 1} & 0.2803 & 0.2269 & 0.5072 & Winner 1 & 0.2764 & 0.2349 & 0.5112 \\
\hline & 0.5681 & 0.4479 & & & 0.5706 & 0.4554 & \\
\hline & 0.5527 & 0.4473 & & & 0.5406 & 0.4594 & \\
\hline & 11.231 & 14,739 & 25,970 & & 4,394 & 5,935 & 10,329 \\
\hline \multirow[t]{5}{*}{ Loser 1} & 0.2131 & 0.2797 & 0.4928 & Loser 1 & 0.2079 & 0.2809 & 0.4888 \\
\hline & 0.4319 & 0.5521 & & & 0.4294 & 0.5446 & \\
\hline & 0.4325 & 0.5675 & & & 0.4254 & 0.5746 & \\
\hline & 26,004 & 26,697 & 52,701 & & 10,234 & 10,898 & 21,132 \\
\hline & 0.4934 & 0.5066 & & & 0.4843 & 0.5157 & \\
\hline
\end{tabular}

The table reports the contingency tables of the aggregate hedge fund sample (ALLHF) for the one-, three-, six-, and 12-month time horizons for the advance notice period case. The two-times-two contingency tables show the proportion of winners and losers in a two-period framework, while the return is used as the performance measure. Each contingency table displays (a) the number of observations in each of the four quadrants, (b) the percentage of specific observations in relation to the total number of observations (in bold letters), (c) the percentage of specific observations in relation to the total number of observations in the column, and (d) the percentage of specific observations in relation to the total number of observations in the rows. The investigation period is from January 1994 to December 2008.

\section{Impact of the Advance Notice Period on Performance Persistence}

Comparing the results of the base case and the ANP case, it is obvious that accounting for advance notice periods significantly reduces performance persistence both on an aggregate and an individual fund level, in particular for shorter time horizons of up to three months. At an individual fund level and based on the 
Chi-square test, the results show that the proportion of persistent funds at the one-month horizon decreases from $18.71 \%$ (base case) to $8.29 \%$ (ANP case) at the 5\% significance level. Figure 1 displays the differences in percentage of persistent funds between the base case and the advance notice period case. The results are shown for five hedge fund strategies separately. Here, the Chi-square test as test method is used with the significance level at 5\%. The period of analysis is from January 1994 to December 2008.

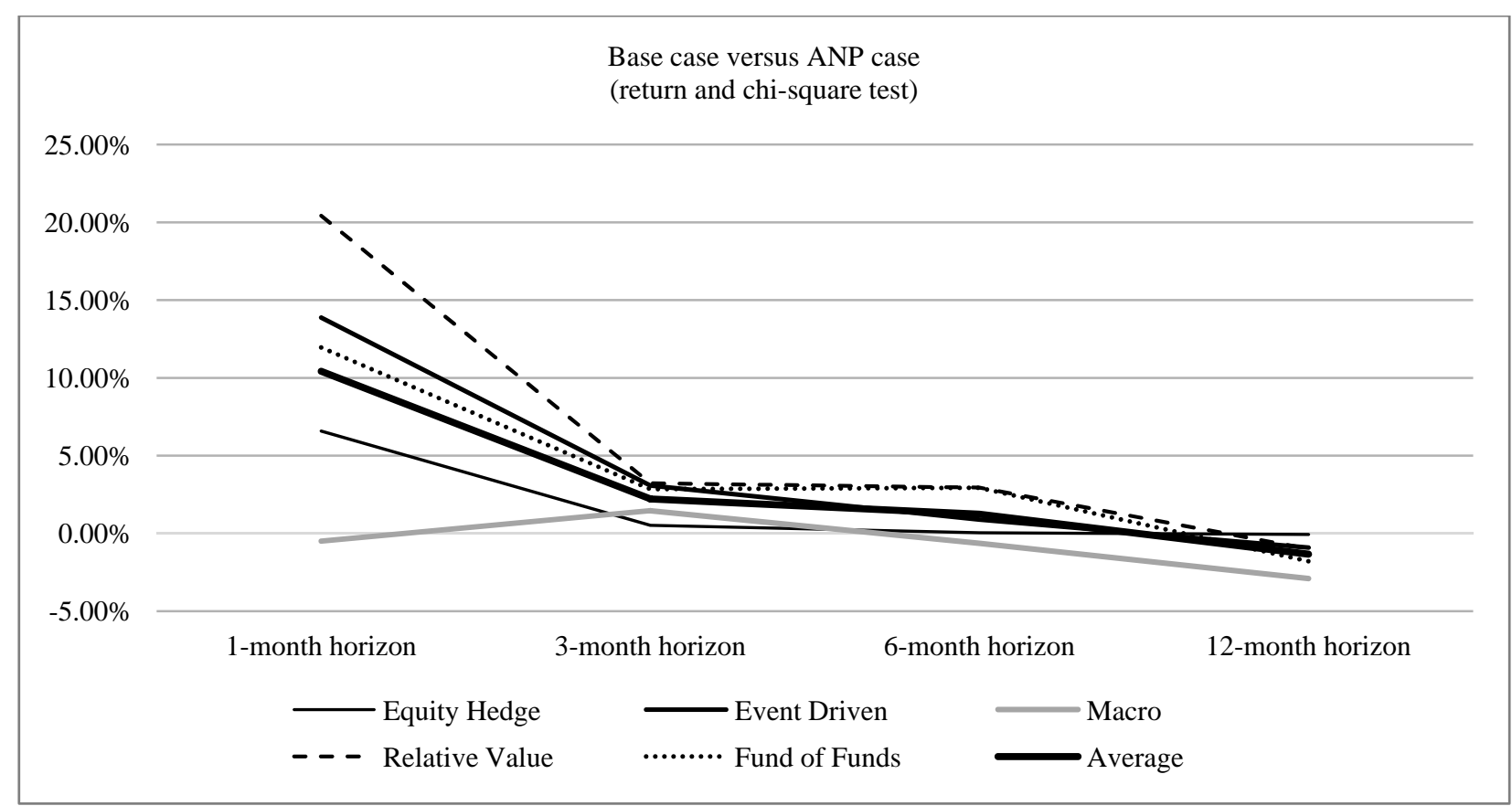

Figure 1. Differences in percentage of persistent funds between the base case and the ANP case.

In fact, the reduction in the proportion of persistent funds appears across funds of all five hedge fund strategies, but is most severe for RV funds. With regard to the test methods, the results show that the Chi-square test, on average, leads to higher levels of performance persistence than the cross-product ratio tests, irrespective of the advance notice period factor. Similar results are obtained with respect to the performance measures. The Sharpe ratio only leads to insignificantly higher levels of persistence than the return for both the base case and the ANP case. Obviously, the advance notice period has no significant impact on the performance persistence results regarding the applied methodology and performance measures. Thus, accounting for the advance notice period primarily has an impact on the results with respect to the time horizon, because the proportion of statistically persistent funds declines considerably at the one-month time horizon, while having only a modest impact on the results for longer time horizons. In other words, performance persistence for individual hedge funds is less affected by the length of the time horizon, when accounting for investor trading restrictions.

Similar to the results on an individual basis, the impact of the advance notice period on performance persistence is also significant at an aggregate fund level. This is particularly true at the one-month time horizon, but is not limited to it. In fact, the aggregate results show for all four analyzed time horizons that the levels of performance persistence are smaller, accounting for the advance notice factor.

Table 7 exhibits the differences between the base case and the advance notice period case with respect to the proportion of the four outcomes (WW, WL, LW, and LL) for the one-, three-, six-, and 12-month time 
horizons at an aggregate level. The proportion of persistent winners (WW) and losers (LL) declines significantly for all four time horizons, for example, when summing up the percentages of persistent winners (WW) and losers (LL) at an aggregate fund level, the differences between the base case and the advance notice period case are as follows: $3.66 \%$ (one-month), $0.71 \%$ (three-month), 2.89\% (six-month), and 1.66\% (12-month). Therefore, accounting for advance notice periods significantly reduces the levels of performance persistence for all time horizons on an aggregate fund level. This finding can be confirmed for all five hedge fund strategies.

Table 7

Aggregate Differences Between the Base Case and the Advance Notice Period Case

\begin{tabular}{lcclcc}
\hline & \multicolumn{2}{c}{ Difference-ALLHF-1-month } & \multicolumn{3}{c}{ Difference-ALLHF-3-month } \\
\hline Base vs ANP & Winner 2 & Loser 2 & Base vs ANP & Winner 2 & Loser 2 \\
\hline Winner 2 & -0.0183 & 0.0193 & Winner 2 & -0.0104 & 0.0082 \\
Loser 2 & 0.0172 & -0.0183 & Loser 2 & 0.0083 & -0.0062 \\
\hline \multicolumn{3}{r}{ Difference-ALLHF-6-month } & & Difference-ALLHF-12-month \\
\hline Base vs ANP & Winner 2 & Loser 2 & Base vs ANP & Winner 2 & Loser 2 \\
\hline Winner 2 & -0.0151 & 0.0159 & Winner 2 & -0.0104 & 0.0082 \\
Loser 2 & 0.0129 & -0.0138 & Loser 2 & 0.0083 & -0.0062 \\
\hline
\end{tabular}

Table 7 reports the aggregate differences between the base case and the advance notice period case with respect to the proportion of the four outcomes (WW, WL, LW, and LL) of the two-times-two contingency tables. Differences are shown at the one-, three-, six-, and 12-month time horizon and are displayed in relative terms, adding up to zero. Here, the return is used as the performance measure. The period of analysis is from January 1994 to December 2008.

To check for robustness of results, the analysis is conducted both for different periods and for the 90th to 10th percentile performance data. Overall, the results of the robustness checks are consistent with the reported findings. Further, the analytical framework integrates other forms of investor trading restrictions such as subscription and redemption intervals. The tests with these additional restrictions also confirm the finding of significantly lower levels of performance persistence.

\section{Conclusions}

In order to fully reap the benefits of potential persistence of hedge fund performance, there should be no restrictions or additional costs associated with hedge fund investments. However, in reality, there are various special conditions connected with investing in hedge funds. One of these fundamental restrictions is the advance notice period, which represents an important form of illiquidity risk to hedge funds investors, since it is likely to particularly hamper investments in turbulent markets. This analysis implemented the individual hedge funds' advance notice periods and tested for performance persistence.

The results document a significantly negative impact of the advance notice period on short-term performance persistence. The existence of advance notice periods substantially reduces the possibility of exploiting persistence effects in hedge fund performance appropriately. In fact, liquidity constraints and the general inability of investors to act immediately on new information support the existence of performance persistence among hedge funds. Overall, the findings have substantial implications both for the investment practice and future research on hedge fund performance persistence, for example, future academic research 
should aim to better integrate specific investment terms such as lock-up periods and the status of funds (e.g., open or closed for new investments) within their analyses of performance persistence.

\section{References}

Ackermann, C., McEnally, R., \& Ravenscraft, D. (1999). The performance of hedge funds: Risk, return, and incentives. Journal of Finance, 54(3), 833-874.

Agarwal, V., \& Naik, N. (2000a). Generalised style analysis of hedge funds. Journal of Asset Management, 1(1), 93-109.

Agarwal, V., \& Naik, N. (2000b). Multi-period performance persistence analysis of hedge funds. Journal of Financial and Quantitative Analysis, 35(3), 327-342.

Agarwal, V., Daniel, N., \& Naik, N. (2005). Role of managerial incentives, flexibility, and ability: Evidence from performance and money flows in hedge funds (Working Paper).

Aragon, G. (2007). Share restrictions and asset pricing: Evidence from the hedge fund industry. Journal of Financial Economics, 83(1), 33-58.

Baquero, G., \& Verbeek, M. (2006). A portrait of hedge fund investors: Flows, performance and smart money (Working Paper).

Baquero, G., Horst, J. R., \& Verbeek, M. (2005). Survival, look-ahead bias and the persistence in hedge fund performance. Journal of Financial and Quantitative Analysis, 40(3), 493-517.

Barès, P. A., Gibson, R., \& Gyger, S. (2003). Performance in the hedge funds industry: An analysis of short and long-term persistence. Journal of Alternative Investments, 6(3), 25-41.

Berk, J., \& Tonks, I. (2007). Return persistence and fund flows in the worst performing mutual funds (Working Paper).

Bollen, N., \& Busse, J. (2004). Short-term persistence in mutual fund performance. Review of Financial Studies, 18(2), 569-597.

Bonadurer, W. (2007). The performance persistence of equity long/short hedge funds. Bern: Haupt.

Boyson, N. (2008). Hedge fund performance persistence: A new approach. Financial Analysts Journal, 64(6), 27-44.

Brown, S., \& Goetzmann, W. (1995). Performance persistence. Journal of Finance, 50(2), 679-698.

Brown, S., Goetzmann, W., \& Ibbotson, R. (1999). Offshore hedge funds: Survival and performance, 1989-1995. Journal of Business, 72(1), 91-117.

Capocci, D., \& Hübner, G. (2004). Analysis of hedge fund performance. Journal of Empirical Finance, 11(1), 55-89.

Carhart, M. (1997). On persistence in mutual fund performance. Journal of Finance, 52(1), 57-82.

Carpenter, J., \& Lynch, A. (1999). Survivorship bias and attrition effects in measures of performance persistence. Journal of Financial Economics, 54(3), 337-374.

Clifford, C. (2008). Value creation or destruction? Hedge funds as shareholder activists. Journal of Corporate Finance, 14(4), 323-336.

Edwards, F., \& Caglayan, M. (2001). Hedge fund performance and manager skill. Journal of Futures Markets, 21(11), $1003-1028$.

Eling, M. (2009). Does hedge fund performance persist? Overview and new empirical evidence. European Financial Management, 15(2), 362-401.

Eling, M., \& Schuhmacher, F. (2007). Does the choice of performance measure influence the evaluation of hedge funds? Journal of Banking \& Finance, 31(9), 2632-2647.

Fung, W., Hsieh, D., Naik, N., \& Ramadorai, T. (2008). Hedge funds: Performance, risk, and capital formation. Journal of Finance, 63(4), 1777-1803.

Gantenbein, P., Glatz, S., \& Zimmermann, H. (2013). Equity markets and the performance of hedge funds: How stable is persistence? GSFT International Journal on Business Review, 2(4), 231-237.

Getmansky, M., Lo, A., \& Makarov, I. (2004). An econometric model of serial correlation and illiquidity in hedge fund returns. Journal of Financial Economics, 74(3), 529-609.

Gibson, R., \& Wang, S. (2009). Hedge fund alphas: Do they reflect managerial skills or mere compensation for liquidity risk bearing (Working Paper)?

Grinblatt, M., \& Titman, S. (1992). The persistence of mutual fund performance. Journal of Finance, 47(5), 1977-1984.

Harri, A., \& Brorsen, B. (2004). Performance persistence and the source of returns for hedge funds. Applied Financial Economics, 14(2), 131-141.

Hedge Fund $\quad$ Research. $\quad$ (2009). $\quad$ Databases. $\quad$ Retrieved from https://www.hedgefundresearch.com/index.php?fuse=database $\$ 1245664265$

Horst, J., \& Verbeek, M. (2007). Fund liquidation, self-selection, and look-ahead bias in the hedge fund industry. Review of 
Finance, 11(4), 605-632.

Jagannathan, R., Malakhov, A., \& Novikov, D. (2007). Do hot hands persist among hedge fund managers? An empirical evaluation (Working Paper).

Koh, F., Koh, W., \& Teo, M. (2003). Asian hedge funds: Return persistence, style, and fund characteristics (Working Paper).

Kosowski, R., Naik, N., \& Teo, M. (2007). Do hedge funds deliver alpha? A Bayesian and bootstrap analysis. Journal of Financial Economics, 84(1), 229-264.

Lhabitant, F. S. (2004). Hedge funds-Quantitative insights. Chichester: John Wiley \& Sons.

Liang, B. (2000). Hedge funds: The living and the dead. Journal of Financial and Quantitative Analysis, 35(3), 309-326.

Malkiel, B., \& Saha, A. (2005). Hedge funds: Risk and return. Financial Analysts Journal, 61(6), 80-88.

Park, J., \& Staum, J. (1998). Performance persistence in the alternative investment industry (Working Paper). 